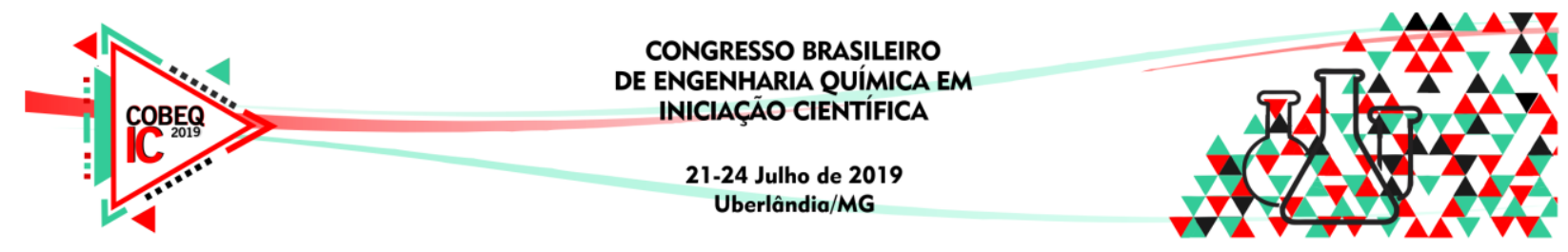

\title{
AVALIAÇÃO DO PROCESSO DE EXTRAÇÃO DO COBRE E PRATA CONTIDOS EM PLACAS DE CIRCUITO IMPRESSO VIA LIXIVIAÇÃO ÁCIDA E RECUPERAÇÃO POR OXIRREDUÇÃO
}

\author{
A.C. SOARES ${ }^{1}$, A.B.S. COSTA ${ }^{1}$, F.F. SALVADOR ${ }^{1}$ e R.C. SOUSA $^{1}$ \\ ${ }^{1}$ Universidade Federal do Espírito Santo, Departamento de Engenharia Rural \\ Centro de Ciências Agrárias e Engenharias - Engenharia Química \\ E-mail para contato: robson.sousa@ufes.br
}

\begin{abstract}
RESUMO - O acentuado crescimento do setor industrial eletrônico ocasiona, ao mesmo tempo, o crescimento dos resíduos de equipamentos eletrônicos, tanto industriais quanto domésticos como, por exemplo, o descarte de equipamentos obsoletos. Esses resíduos eletrônicos por sua vez podem ser reciclados e os metais neles contidos, recuperados, possibilitando redução no impacto ambiental gerado pelo seu descarte inadequado, além de promover economia na exploração das reservas naturais. Dentro desse contexto, o presente trabalho, avaliou a recuperação do cobre e da prata a partir de placas de circuito impresso de equipamentos eletrônicos por meio de processos físicos e químicos, em que o tamanho das placas foram reduzidos, em seguida, realizado a lixiviação em meio ácido, utilizando ácido nítrico diluído, tendo como resultado a lixiviação acima de $75 \%$ do cobre e $90 \%$ da prata contido nas placas. Esses metais solubilizados foram recuperados com técnica de oxirredução, utilizando ferro metálico, possibilitando a recuperação acima de $90 \%$ do cobre e $99 \%$ da prata em solução. Para quantificar os metais em solução e o recuperado, foi utilizada a técnica de espectrofotometria de absorção atômica.
\end{abstract}

\section{INTRODUÇÃO}

Atualmente, os setores industriais que mais crescem em todo o mundo, devido à rápida evolução tecnológica e a expansão do mercado mundial, são as empresas fabricantes de materiais eletrônicos. Acompanhando esse crescimento, aumenta ao mesmo passo a quantidade de lixo eletrônico produzido, conhecido também como resíduo eletroeletrônico, chegando a 44,7 milhões de toneladas em 2016 e com previsões para que nos próximos anos esse número ultrapasse a casa de 50 milhões de toneladas. O Brasil foi o segundo país que mais gerou resíduo eletrônico nas Américas, produzindo cerca de 1,5 milhões de toneladas. Grande parte desses resíduos são descartados de maneira irregular, ocasionando contaminação do meio ambiente (Baldé et al., 2017).

Equipamentos eletroeletrônicos são compostos por todo equipamento que necessita de uma corrente elétrica para seu pleno funcionamento, por exemplo, televisões, celulares, 


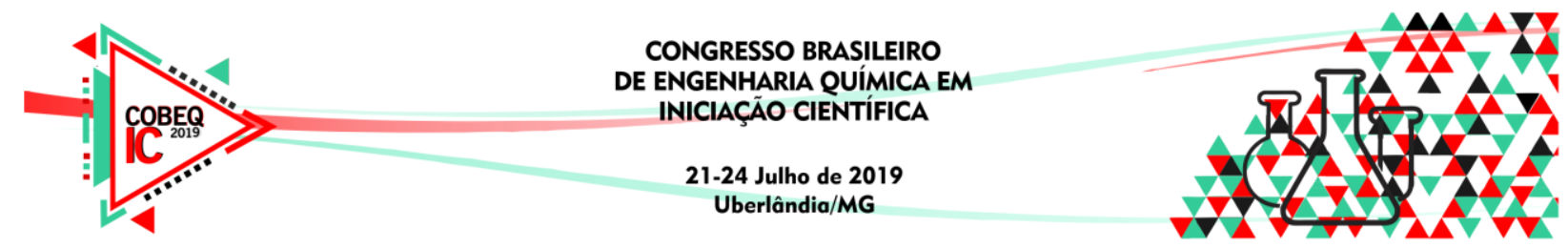

computadores e máquinas de lavar. Quando esses equipamentos são descartados, por algum defeito ou por estarem obsoletos, se classificam como resíduos eletroeletrônicos. Esses equipamentos são compostos por uma carcaça polimérica ou metálica, componentes externos e placas de circuito impresso. As placas de circuito impresso (PCI) podem compor mais de $25 \%$ da massa de todos os produtos fabricados. Sua composição é extremamente heterogênea, contendo uma série de metais $(\mathrm{Cu}, \mathrm{Ni}, \mathrm{Sn}, \mathrm{Pb}$ e metais nobres), de alto valor agregado, além de materiais poliméricos e cerâmicos (Yellishetty et al. 2011; Tenório, 2012; Tomasek et al., 2000; Veit et al., 2002). Através de um tratamento adequado, os resíduos eletroeletrônicos podem ser reaproveitados, isso porque os equipamentos eletrônicos são normalmente compostos por uma carcaça metálica ou plástica, cabos elétricos e placas de circuito impresso (PCI), os quais são em sua maioria recicláveis (Mattos, 2008; Willian e Willians, 2007).

No caso do cobre, estudos mostram que a quantidade de cobre contida nas PCI's pode chegar até 30\% da sua composição (Veit, 2005; Moraes, 2011). Percentual esse significativo quando comparado com a exploração nas fontes naturais, representada por apenas $3 \%$ do metal (Veit, 2005). Considerando uma tonelada de minério, de fontes primárias retira-se até 30 quilos de cobre, enquanto que por outro lado, tomando a mesma base de cálculo (1 ton) em PCI esse valor pode chegar até 300 quilos. Em relação a prata, a porcentagem nas fontes primárias são em torno de 0,07\% em massa, e nas PCI's pode alcançar 0,03\% (Mello, 2017; Oliveira, 2012). Ambos são metais de muita aplicação e elevado valor comercial.

Dentre as diversas técnicas de solubilização de metais das PCI's, o processo de lixiviação utilizando ácido nítrico $\left(\mathrm{HNO}_{3}\right)$, que segundo trabalhos analisados, apresentou resultados satisfatórios para a recuperação de cobre e prata (Moraes 2011; Oliveira, 2012; Mello 2017).

Após a etapa de lixiviação usando o ácido nítrico, a recuperação dos metais solubilizados se tem pelo processo de oxirredução, conhecido também como cementação. Essa técnica consiste em utilizar um metal, em sua forma metálica (reduzida) para precipitar outro metal que se encontra em sua forma iônica na solução. Esse processo ocorre espontaneamente quando esses metais entram em contato (Jackson, 1986).

Diante do que foi apresentado, verifica-se a importância de aplicar o processo de extração dos metais contidos nas placas de circuito impresso, tanto por razões de natureza ambiental e de conservação de recursos quanto devido ao valor econômico dos metais de base e preciosos nelas contidos. Desta forma, propõe-se avaliar o processo de extração do cobre e prata nas PCI via lixiviação com ácido nítrico, o qual será recuperado por oxirredução com ferro metálico. Todas as análises quantitativas desses metais foram conduzidas pela técnica de espectrometria de absorção atômica com chama.

\section{METODOLOGIA}

Nesse trabalho foram utilizadas 4 placas de circuito impresso do tipo motherboard de computadores de diferentes marcas, modelos e ano de fabricação, com o intuito de obter variação de composição. As PCI's passaram por um processo de limpeza e os dissipadores de calor foram retirados. Após isso, foram desmanteladas, ou seja, todos os componentes soldados/colados na superfície foram retirados, utilizando um soprador térmico. Em seguida, 


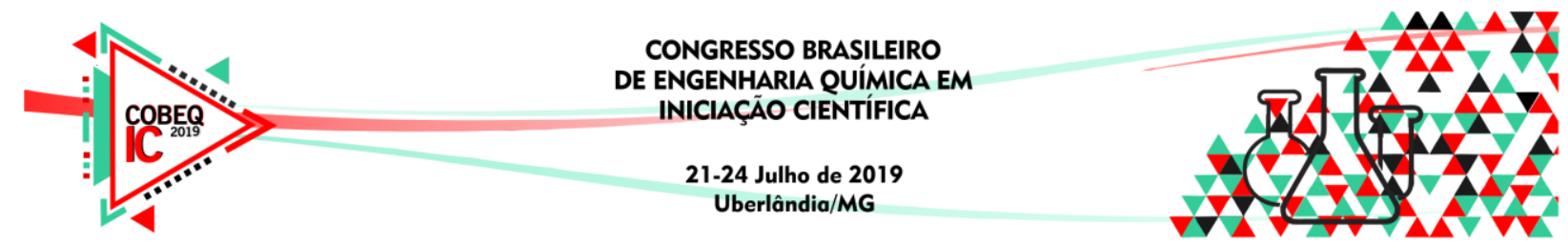

estas placas foram fragmentadas em partes menores que $2 \mathrm{~cm}$ e levadas para um moinho de faca, modelo SL32, Solab, a fim de obter partículas menores de $1 \mathrm{~mm}$. Após a fragmentação, as PCI's foram peneiradas utilizando peneira de $1 \mathrm{~mm}$ de abertura (16 TYLER/MESH). A fração retida na malha da peneira passou por mais um estágio de fragmentação até todo material estivesse com granulometria inferior a $1 \mathrm{~mm}$. $\mathrm{O}$ processo de moagem das placas fragmentadas foi realizado no Departamento de Engenharia Química da Universidade Federal de Itajubá - Itajubá/MG.

Com a placa de circuito impresso fragmentada $(<1 \mathrm{~mm})$, foi realizada a separação magnética passando todo material por um tubo metálico medindo 1 metro de comprimento com campo magnético. A vazão do material ficou fixada em $60 \mathrm{~g} / \mathrm{min}$ e a separação foi realizada em triplicata com a finalidade de garantir a retirada de todo material magnético da amostra. Essa etapa foi realizada no Laboratório da Engenharia Química do Campus de Alegre.

\subsection{Caracterização das Placas de Circuito Impresso}

Para a caracterização foi usado o método de digestão em água régia, a fim de solubilizar todo o cobre e a prata, os quais em seguida foram quantificados pela técnica de Espectrometria de Absorção Atômica com Chama. A água régia (proporção de 3:1 de $\mathrm{HCl}$ : $\mathrm{HNO}_{3}$ ) foi adicionada ao material proveniente do tratamento mecânico na proporção de $1 \mathrm{~g}$ para $20 \mathrm{~mL}$ de água régia. Nessa etapa $10 \mathrm{~g}$ de material foram colocados em contato direto com $200 \mathrm{~mL}$ de solução. A digestão em água régia foi feita em temperatura ambiente durante $24 \mathrm{~h}$ e realizada em triplicata. Após este período, o resíduo sólido foi separado do lixiviado por filtração simples. Foram coletadas amostras de $2 \mathrm{~mL}$ das soluções lixiviadas em seguida diluídas até 1 litro usando um balão volumétrico para análise da quantidade de cobre e prata.

Para o processo de lixiviação das placas, foram pesadas amostras de $10 \mathrm{~g}$ de PCI, em seguida, misturadas com $200 \mathrm{~mL}$ de solução (relação 1 para 20 de sólido e líquido), utilizando ácido nítrico 2 mol. $\mathrm{L}^{-1}$ a uma temperatura de $60{ }^{\circ} \mathrm{C}$, como descrito na literatura (Moraes, 2011; Oliveira 2012). Para a reação foi utilizado um agitador magnético com aquecimento, por um período de 4 horas em balão de fundo chato de $500 \mathrm{~mL}$ com um condensador de bolas de $300 \mathrm{~mm}$ para refluxo dos vapores ácidos produzidos. Ao término do período de lixiviação o subproduto sólido foi separado do líquido utilizando papel de filtro quantitativo por filtração a vácuo. Esse ensaio foi realizado em triplicata.

Para a caracterização do lixiviado, foram coletadas alíquotas de $2 \mathrm{~mL}$ e diluídas até 1L. Em seguida o cobre e prata solubilizados foram quantificados por meio da técnica de Espectrometria de Absorção Atômica com Chama.

Após a lixiviação, realizada no processo anterior, foi usado ferro metálico no processo de cementação desses metais. Para definir a quantidade de ferro necessário, foram usadas como base as reações de oxirredução desses metais, mas com o proposito da máxima cementação, esse valor foi em excesso. O ferro metálico foi misturado a $100 \mathrm{~mL}$ das soluções em temperatura ambiente $\left(25^{\circ} \mathrm{C}\right)$ sob agitação magnética por 24 horas. Após esse período, utilizando filtração a vácuo e papel de filtro quantitativo, foi separado o líquido do sólido. 


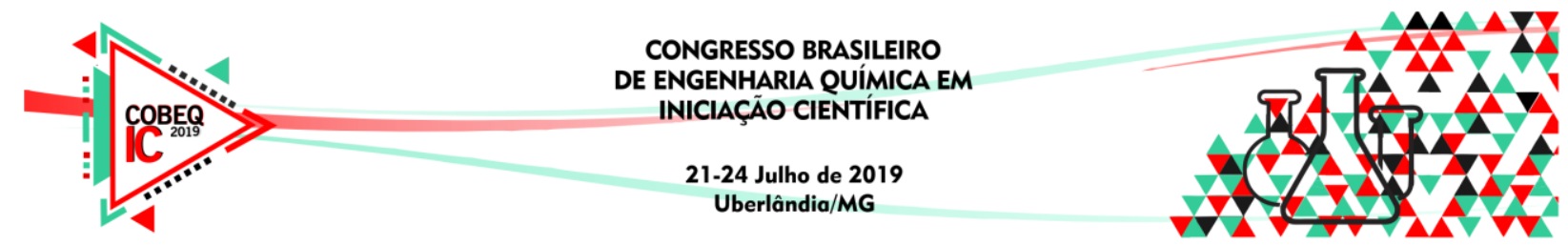

Para quantificar e coletar o cobre e a prata foram coletadas amostras de $2 \mathrm{~mL}$ das soluções após a cementação para análise da quantidade dos metais em questão restante na solução utilizando Espectrometria de Absorção Atômica com Chama. A quantidade de cobre e prata precipitada foi calculada pela diferença entre a quantidade total que havia inicialmente na solução e a quantidade desses metais restantes no lixiviado.

\section{RESULTADOS E DISCUSSÃO}

Foram pesadas 900 gramas de PCI's antes da fragmentação. Após essa etapa o obtevese 889,25 gramas de placa triturada, uma perda de aproximadamente $10,75 \mathrm{~g}$ sendo $1,2 \%$ do total. Provavelmente perdas por material suspenso no funcionamento do equipamento devido a sua baixa granulometria. Todo material ficou classificado como menor que $1 \mathrm{~mm}$, pois passou por completo na peneira de $16 \mathrm{MESH}$.

A fração magnética representou 2,79\% das PCI's. Mesmo sendo pequena a porcentagem, poder ser considerado um importante resultado, pois esse material separado é rico em ferro e níquel, sendo eles elementos muito magnéticos e que compõe grande parte das PCI's.

Após 24 horas, a temperatura ambiente, as 3 amostras de $10 \mathrm{~g}$ foram analisadas a fim de quantificar o cobre e prata presentes nas soluções. Os resultados das concentrações de cobre e prata são apresentados na Tabela 1.

Como pode-se observar, a média das concentração de cobre na solução foi de 11,33 g.L $\mathrm{L}^{-}$ ${ }^{1}$. Com isso, a porcentagem desse metal nas placas de circuito impresso analisadas, em média, foi de 22,67\%. Comparando com os trabalhos de Veit (2005) e Yamane (2012), que encontraram a porcentagem de cobre nas placas de circuito impresso, respectivamente, de 21,19 e $23,88 \%$, os resultados obtidos foram satisfatórios.

Tabela 1 - Quantidade de cobre e prata nas PCI's

\begin{tabular}{|c|c|c|c|}
\hline Amostras & $\mathbf{1}$ & $\mathbf{2}$ & $\mathbf{3}$ \\
\hline $\begin{array}{c}\text { Concentração de cobre } \\
\left(\mathrm{g} . \mathrm{L}^{-1}\right)\end{array}$ & 10,91 & 12,08 & 11,01 \\
\hline $\begin{array}{c}\text { Porcentagem do cobre } \\
(\%)\end{array}$ & 21,83 & 24,16 & 22,01 \\
\hline $\begin{array}{c}\text { Concentração de prata } \\
\left(\mathrm{g} . \mathrm{L}^{-1}\right)\end{array}$ & 0,00140 & 0,00148 & 0,00143 \\
\hline $\begin{array}{c}\text { Porcentagem de prata } \\
(\%)\end{array}$ & 0,0280 & 0,0310 & 0,0286 \\
\hline
\end{tabular}

Em relação à prata, a média das concentrações foi de 0,001446 g. $\mathrm{L}^{-1}$. A porcentagem média desse metal nas placas foi de 0,0292\%. Analisando os trabalhos de Mello (2017) e Oliveira (2012), suas caracterizações apresentam porcentagem de prata nas placas de circuito impresso, respectivamente, de 0,04 e $0,02 \%$, mostrando que o resultado obtido está de acordo com a literatura. Observa-se também que houve pouca variação na concentração dos metais nas amostras estudadas, demonstrando que esses resultados podem ser considerados reprodutíveis. 


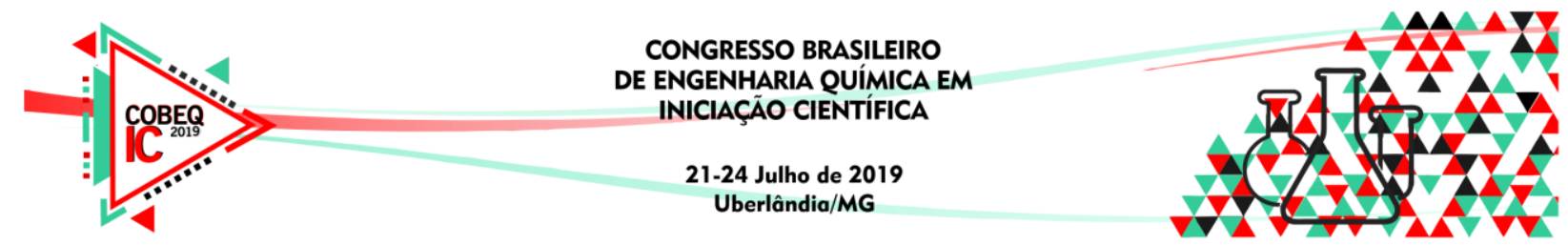

Os resultados da caracterização do cobre e da prata estão apresentados na Tabela 2. Como observado, a concentração média de cobre extraída pelos ensaios foi de 8,70 g.L $\mathrm{L}^{-1}$ e com lixiviação média de $76,81 \%$. Em relação à prata, concentração média extraída pelos ensaios foi de 0,001313 g.L - $^{-1}$ e com lixiviação média de $91,83 \%$ da prata nas PCI's.

Tabela 2 - Concentrações de cobre e prata lixiviado das PCI's

\begin{tabular}{|c|c|c|c|}
\hline Amostras & $\mathbf{1}$ & $\mathbf{2}$ & $\mathbf{3}$ \\
\hline $\begin{array}{c}\text { Concentração de cobre } \\
\left(\mathrm{g} . \mathrm{L}^{-1}\right)\end{array}$ & 8,52 & 9,18 & 8,41 \\
\hline Lixiviação (\%) & 75,19 & 81,02 & 74,22 \\
\hline $\begin{array}{c}\text { Concentração de prata } \\
\text { (g.L } \text { (-1) }^{-1}\end{array}$ & 0,00134 & 0,00129 & 0,00131 \\
\hline Lixiviação (\%) & 93,70 & 90,20 & 91,60 \\
\hline
\end{tabular}

Considerando a estequiometria das reações de oxirredução e levando em conta o uso de $100 \mathrm{ml}$ de solução para a cementação dos metais, para o cobre, de concentração média de 8,70 g. $\mathrm{L}^{-1}$, são necessários $0,765 \mathrm{~g}$ de ferro e em relação a prata, com concentração média de 0,001313 g. $\mathrm{L}^{-1}$, seriam necessários $3,4 \times 10^{-5} \mathrm{~g}$ de ferro. Com o propósito de total recuperação, foi usado $1 \mathrm{~g}$ de ferro metálico em pó.

Após passado o tempo estipulado na cementação, o cobre e prata precipitado misturado com o ferro restante foi filtrado com papel quantitativo. Os resultados das porcentagens de recuperação para o cobre e prata estão apresentados na Tabela 3 a seguir.

Tabela 3 - Quantidade de cobre e prata restantes e os percentuais de recuperação

\begin{tabular}{|c|c|c|c|}
\hline Amostras & $\mathbf{1}$ & $\mathbf{2}$ & $\mathbf{3}$ \\
\hline $\begin{array}{c}\text { Concentração de cobre } \\
\left(\mathrm{g} . \mathrm{L}^{-1}\right)\end{array}$ & 0,66 & 0,87 & 0,60 \\
\hline Recuperação (\%) & 92,25 & 90,52 & 92,86 \\
\hline $\begin{array}{c}\text { Concentração de prata } \\
\left.\text { (g.L } \text { - }^{-1}\right)\end{array}$ & 0,00001 & 0,00001 & 0,00001 \\
\hline Recuperação (\%) & 99,92 & 99,92 & 99,92 \\
\hline
\end{tabular}

Como observado, a recuperação por cementação usando ferro ficou acima de $90 \%$ para o cobre e para a prata acima de $99 \%$. Isso mostra que o ferro para recuperar esses metais em solução é bem eficaz.

\section{CONCLUSÃO}

A lixiviação utilizando ácido nítrico diluído mostrou que a solubilização do cobre ficou acima de $75 \%$ em todos os ensaios e para a prata, ficando próximo a $90 \%$, mostrando assim a eficácia desse lixiviante. Por ser diluído, se tem uma economia de reagente, ponto importante no processo.

A recuperação por cementação utilizando ferro metálico se mostrou muito eficiente, considerando que a recuperação do cobre ficou acima dos $92 \%$ e para a prata, superior a $99 \%$ em todas as replicas. 


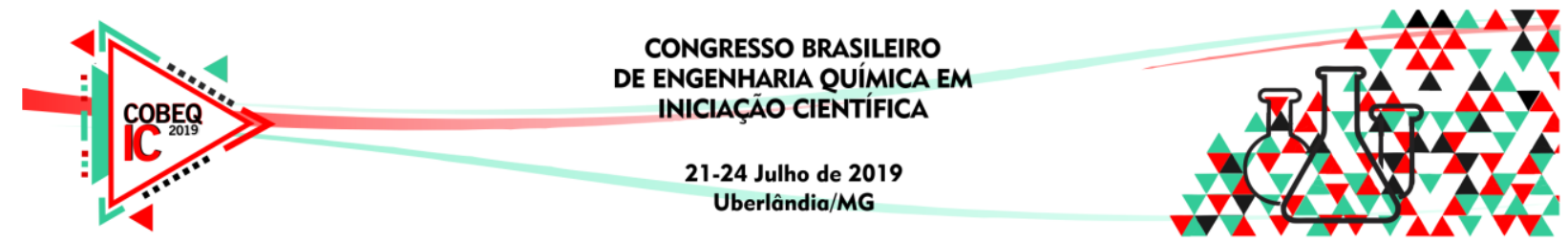

\section{REFERÊNCIAS}

BALDÉ, C.P., FORTI V., GRAY, V., KUEHR, R., STEGMANN,P.: “The Global E-waste Monitor - 2017”, United Nations University (UNU), International Telecommunication Union (ITU) \& International Solid Waste Association (ISWA), Bonn/Geneva/Vienna.

JACKSON, E.. Hydrometallurgical extraction and reclamation. Ellis Horwood Limited, New York, p. 29-39, 1986.

MELO, R. A. C. de - Estudo da lixiviação de placas de circuito impresso de computadores desktops obsoletos da UFRN. Dissertação de Mestrado, UFRN, PPGEQ, Área de Concentração: Engenharia Química, Natal, Brasil, 2017.

MORAES, V. T. Recuperação de metais a partir do processamento mecânico e hidrometalúrgico de placas de circuito impresso de celulares obsoletos. Tese (Doutorado) - Escola Politécnica, Universidade de São Paulo, São Paulo, 2011.

OLIVEIRA, Paula Cristina Filipe de. Valorização de Placas de Circuito Impresso por Hidrometalurgia. 2012. 320 f. Tese (Doutorado) - Curso de Engenharia do Ambiente, Universidade Técnica de Lisboa Instituto Superior Técnico, Lisboa, 2012.

TENÓRIO, J. A. S. Production of non-ferrous metallic concentrates from electronic scrap. Minerals, metals and materials society/AIME (USA). p. 505-509, 1997.

TOMASEK, K., VADASZ, P. e RABATIN, L. "Gold extration from the electronical scrap". Slovak Republic. v. 6, n. 2, p. 116-124, 2000.

VEIT, H. M., PEREIRA, C. D. e BERNARDES, A.M. "Using mechanical processing in recycling a printed wiring boards". JOM. v. 54, n. 6, p. 45-47. 2002.

VEIT, H. M. Reciclagem de cobre de sucatas de placas de circuito impresso. Tese (Doutorado) - Programa de Pós-Graduação em Engenharia de Minas, Metalúrgica e de Materiais, Escola de Engenharia, Universidade Federal do Rio Grande do Sul, Porto Alegre, 2005.

YAMANE, L. H. Recuperação de metais de placas de circuito impresso de computadores obsoletos através de processo biohidrometalúrgico. Tese (Doutorado) - Escola Politécnica, Universidade de São Paulo, São Paulo, 2012.

YELLISHETTY, M.; MUDD, G. M.; RANJITH, P. G.; THARUMARAJAH, A.; Environ. Sci. Policy 2011, 14, 650. GERBASE, A. E.; OLIVEIRA, C. R.; Quim. Nova 2012, 35, 1486.

WILLIAM, J. H. e WILLIAMS, P.T. Separation and recovery of materials from scrap printed circuit boards. Resources Conservation and Recycling. v. 51, p. 691-709, 2007. 